\title{
Percentage of Body Fat and Weight Gain in Participants in the Tehran High School Wrestling Championship
}

\author{
Ramin Kordi, MD, PhD; Ruhollah Nourian, MD; Mohsen Rostami; W. Angus Wallace, MD
}

\author{
Authors' Affiliation: \\ 1. Sports Medicine Research Center, \\ Tehran University of Medical \\ Sciences, Tehran, Iran \\ 2. Division of Orthopedic and \\ Accident Surgery, University of \\ Nottingham, Nottingham, UK

\begin{abstract}
* Corresponding Authors;
Address: Sports Medicine Research Centre, No 7, Al-e-Ahmad Highway, Tehran, P.O Box: 14395-578, Iran

E-mail: noorian@farabi.tums.ac.ir
\end{abstract}

Received: Nov 06, 2011

Accepted: Jan 02, 2012

Key Words: Wrestling; Body Fat; Weight Loss; Weight Gain

\begin{abstract}
Purpose: Weight loss in wrestling has been found to be an interesting issue for researchers. In this regard, complications of weight loss in wrestlers before the competitions and their weight gain in course of competitions have been debated in previous studies. The objective of this study was to investigate the extent of weight gain and to estimate the percentage of body fat in participants in the Tehran high school male wrestling championship.

Methods: This study was a cross sectional survey. Subjects were participants of the Tehran high school male wrestling championship $(n=365)$. Weight gain in course of competitions and body fat levels (based on skin fold measurements) of subjects were measured.

Results: Between the first weigh-in of the wrestlers which was done one day before the competitions and the second weigh-in which was conducted immediately before the first round of their first competition ( 20 hours), $69 \%$ of subjects gained on average $1.3 \pm 0.9 \mathrm{~kg}$ (range: 0.1 to $6.10 \mathrm{~kg}$ ) or $2.2 \pm 1.7 \%$ of the wrestler's weight (range: 0.1 to 9.3). Among the subjects, the mean of fat body percentage was found to be $\mathbf{1 5 . 2 \%}$.

Conclusions: Rapid weight loss for matches was prevalent among subjects. It was also found that Iranian wrestlers have a relatively higher body fat percentage in comparison to American wrestlers. Therefore, it can be concluded that weight loss behavior of these wrestlers should be changed from using dehydration methods to using gradual methods of weight loss such as fat reduction methods.
\end{abstract}

Asian Journal of Sports Medicine, Volume 3 (Number 2), June 2012, Pages: 119-125

\section{INTRODUCTION}

$\mathrm{W}$ restling is considered as one the first sports included in the original Olympic Games. Health care providers are concerned about wrestling specific injuries and also related medical conditions such as skin infections, blood born infections, nutritional issues and weight loss ${ }^{[1-8]}$. Weight loss in wrestling has been a concern for researchers and health care professionals for more than half a century ${ }^{[9]}$. It is reported that wrestlers often practice weight loss in order to be certified in a lower competitive weight class ${ }^{[10-12]}$. Wrestlers and coaches believe that wrestling in the lowest possible weight class gives them a competitive advantage ${ }^{[13]}$. Moreover, "weight loss" helps wrestling coaches to complete their weight-class roster and put their best wrestlers in selected weight classes ${ }^{[14]}$.

Wrestlers may reduce their body mass gradually or rapidly before the matches ${ }^{[7]}$. In a "rapid weight loss" regime, wrestlers reduce their body mass within a few days before the matches. For rapid weight loss, high school wrestlers in the US began reducing their body mass on average $4.0 \pm 2.1$ days (Mean $\pm \mathrm{SD}$ ) before their matches, though over half of them began their weight loss process only three days or less before the matches ${ }^{[11]}$. "Rapid weight loss" mainly leads to a loss of body water and glycogen that would be replaced within a few hours or days following the pre-match 
weigh-in ${ }^{[15,16]}$. A "gradual weight loss" regime involves wrestlers reducing their body mass over several weeks or months. The aim of this regime is to reduce body fat ${ }^{[17,18]}$.

Official weigh-ins normally take place 0.5 to 20 hours before the competition ${ }^{[9]}$. Depending on the amount of time available between the weigh-in and competition, wrestlers might increase their weight to a point that they are competing at a body weight greater than the weight class limit. The weight gain might lead to a body mass discrepancy between the opponents and give a competitive advantage to the wrestler ${ }^{[19]}$.

The magnitude of weight gain after the weigh-in is primarily related to the amount of weight loss that the wrestler had before the weigh-in ${ }^{[20]}$. Therefore, the magnitude of weight gain can be used as an indicator of the magnitude of the weight loss that was achieved by rapid weight loss methods (mainly dehydration methods). However, in the period between weigh-in and competition, the wrestlers may not be able to restore all the fluid and glycogen especially in severely dehydrated individuals ${ }^{[20]}$. fluid homeostasis might take 24 to 48 hours, and replenishing muscle glycogen might takes as long as 72 hours in some cases ${ }^{[9]}$. Therefore, the magnitude of weight gain might be less than the actual amount of weight loss.

Scott et al ${ }^{[20]}$ reported that collegiate wrestlers in the US gained an average of $3.3 \pm 1.5 \mathrm{~kg}$ between the official weigh-in and an approximately $20 \mathrm{~h}$ later, before the first round of the first competition in the tournament. It accounted for $4.9 \pm 2.4 \%$ of wrestlers' body mass. They reported that $95 \%$ of all wrestlers gained at least $0.5 \mathrm{~kg}$ of weight.

Alderman et al ${ }^{[21]}$ studied the rapid weight loss practices by high school wrestlers who participated in international style wrestling in the US. They reported that subjects who were randomly selected from the participants in the 1997 -1998 National Wrestling Championships in the US (aged between 15-18 years), gained an average of $3.4 \mathrm{~kg}$ (range: -2.68 to $+16.73 \mathrm{~kg}$ ) between weigh-in and competition. This represents a $4.81 \%$ gain of body weight (range: $-2.1 \%$ to $13.4 \%$ ). The magnitude of weight loss (weight gain = about $5 \%$ of wrestler's weight) in high school wrestlers who participated in international style wrestling was similar to weight loss in high school wrestlers before the implementation of the new NCAA rule which prohibited some methods of weight loss and set a minimum weight limit (based on $5-7 \%$ of body fat) for the wrestlers ${ }^{[21]}$.

Wroble and Moxley ${ }^{[19]}$ reported that the mean weight gain for high school wrestlers in the US was 1.3 $\pm 1.1 \mathrm{~kg}$ (Range: $-2.0 \mathrm{~kg}$ to $+4.4 \mathrm{~kg}$ ). This corresponds to $2.2 \pm 1.7 \%$ of body mass (Range: -2.6 to +7.2 ). The time between official weigh-in and competition in this study was about $12 \mathrm{~h}$.

The mean percentage of body fat in high school and collegiate wrestlers in the US, as reported by different studies, varies from $6 \%$ to $12.8 \%$; with a reported body fat ranging from $2.4 \%$ to $33.7 \%{ }^{[9,22-26]}$. The percentage of body fat in wrestlers might indirectly show the severity of weight reduction in wrestlers who employed fat reduction methods (gradual weight loss).

Major wrestling associations in the US set a rule for prevention of weight loss based on the percentage of body fat. They recommend a minimum wrestling weight calculated as weight at $5 \%$ to $7 \%$ body fat. In other words, there is a lower limit for percentage of body fat for the high schools and college wrestlers in the US. To date, similar rules have not been established at an international level.

To our knowledge, the percentage of the body fat in Iranian wrestlers has not been studied and more studies are needed in this area. This is essential for planning preventive policies to control the weight loss behaviors of wrestlers in Iran.

Therefore, with the following objectives, we run this study: 1) To investigate the extent of weight gain in participants in the Tehran high school wrestling championship between the official weigh-in and the first round of wrestling at the tournament (about 20 hours). 2) To estimate the percentage of body fat among Participants in the Tehran high school wrestling championship.

\section{METHODS AND SUBJECTS}

This study was a cross sectional survey. Weight-gain of participants in the Tehran High School Championship 
was measured. Percentage of body fat in these groups of wrestlers was measured.

Subjects were wrestlers qualified for the Tehran High School Championship (500 wrestlers) and agreed to participate in the study. This wrestling competition was selected because our pilot study suggested that the majority of wrestlers in Tehran are high school students. In addition, the majority of available data on the weight loss practice of wrestlers in competition are from research carried out on high school and college wrestlers and hence could be employed for comparison between weight loss practice among high school wrestlers in Tehran and high school wrestlers in the US.

\section{Weight gain in competitions:}

The management committee of the "Tehran High School Wrestling Championship" agreed to help with the study. An explanation was given to the wrestlers about the aims and protocols of the research. A verbal consent was obtained from the qualifiers for the "Tehran High School Wrestling Championship" prior to the study. Wrestlers in the heavy weight class usually do not reduce their weight and rarely gain weight ${ }^{[20]}$. Therefore, wrestlers who practise in heavy weight classes were excluded from the study.

The body mass of the subjects was recorded at the official weigh-in and again immediately before the first round of the competition in the tournament. In this regard, there were approximately 20 hours between two weigh-ins of the wrestlers. The official weigh-in was held the day before that of the tournament. Total body weight was recorded at each time to the nearest $0.1 \mathrm{~kg}$.

The mobile model of the Bascule Sahand Electrical scale was employed to weigh wrestlers ${ }^{[27]}$. This scale has a 20 gram division, is approved by the Iranian National Federation of Amature Wrestling, and was used for recording the official weights in this tournament ${ }^{[27]}$. The wrestlers were weighed wearing light shorts at the weigh-in. The same scale was used to re-weigh wrestlers before their matches. Wrestlers were re-weighed within 1 hour before the matches with the same clothing (light shorts).

From the results of the two weigh-ins, the magnitude of weight gained (WG) and percentage of weight gain (PWG) were calculated.

Weight gain and percentage of weight gain are defined in the following box.

Weight gain $=$ Match weight* - Official weight

Percentage of weight gain $=($ weight gain $/$ official

weight) $\times 100$

*the weight of the wrestlers recorded in the second weigh-in

\section{Body fat measurement:}

The percentage of body fat of the subjects was calculated measuring skin fold thickness. The method recommended by the National Collegiate Athletic Association of the US (NCAA) was employed for the skin fold thickness measurement. This involved measuring skin-fold thickness in three sites (triceps, subscapular, and abdominal) and using Lohman's equation for calculation of percentage of body fat ${ }^{[7]}$. It has been shown that this method is valid and reliable for the estimation of body fat levels in wrestlers $[25,26,28,29]$. Skin fold measurements were obtained in the following manner ${ }^{[24,30]}$ :

S1. Triceps site: Longitudinal fold on the posterior midline of the upper arm midway between the posterior lateral aspect of the acromion and proximal border of the olecranon processes

S2. Subscapular site: A diagonal fold taken $1 \mathrm{~cm}$ below the inferior angle of the scapula

S3. Abdominal site: Longitudinal fold taken at a lateral distance of approximately $3 \mathrm{~cm}$ from the umbilicus

Thorland's modification of Lohman's equation that has been validated for college and high school wrestlers was employed to calculate the body density of subjects (Table 1) ${ }^{[24,26,31]}$. Body density was then converted to percent body fat (\%BF) using Brozek's equation that has been validated for wrestlers (Table 1) [25].

Two expert assessors in skin-fold measurements (two physical therapists with more than 10 years experience in measurement of skin fold thickness employing calipers) helped us with measuring the skinfolds of subjects. We did not undertake inter-rater and intra-rater reliability tests for these people. This is a limitation for this part of our study. Standardization 
Table 1: Method used for calculation of percentage of body fat in wrestlers ${ }^{[24,26,31]}$

\section{Parameter}

Skin fold measurements

Calculation of wrestler's body density (BD)

Calculation of wrestler's percent body fat (\%BF)

a Thorland modification of Lohman equation

b Brozek equation

procedures have been established to increase the accuracy and reliability of the skin-fold measurements [29].

Skin-fold thickness was determined to the nearest $0.2 \mathrm{~mm}$ using a Lafayette skin-fold caliper (Model 01127; Lafayette Instrument Company, Lafayette, IN 47903, USA). Lafayette calipers are one of the high quality calipers that have been recommended for measuring skin folds in wrestlers ${ }^{[29]}$.

Thermal dehydration assumptions are necessary for the accurate prediction of skin fold thickness ${ }^{[32]}$. Therefore, we measured the skin folds of the subjects on the day of competition instead of weigh-in.

The Ethics Committee of our university approved this study. All participants gave written informed consent before data collection began.

\section{Method for measurement or calculation}

S1: Triceps, S2: Subscapular, S3: Abdominal

$\mathrm{BD}=1.0973-[0.000815(\mathrm{~S} 1+\mathrm{S} 2+\mathrm{S} 3)]+\left[0.00000084(\mathrm{~S} 1+\mathrm{S} 2+\mathrm{S} 3)^{2}\right]^{\mathrm{a}}$

$\% \mathrm{BF}=[(4.57 / \mathrm{BD})-4.142] \times 100^{\mathrm{b}}$

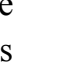

Seventy three percent of the participants in the Tehran High School Championship (365 of 500 wrestlers) agreed to participate in the study.

During the 20 hours (approximately) between the weigh-in and the first round of competition, $68.8 \%$ of the subjects gained a mean of $1.3 \pm 0.9 \mathrm{~kg}$ (Range: 0.1 $6.10 \mathrm{~kg}$ ). This weight gain constituted on average $2.2 \pm 1.7 \%$ of wrestler's weight (Range: 0.1-9.3) (Fig. $1)$. The rest of the subjects (31.2\%) either had a similar body mass or had a weight loss of up to $-2.8 \mathrm{~kg}$.

The mean percentage of body fat in the subjects was $15.2 \pm 9.4 \%$ (95\% of confidence interval, 14.2 to 16.1 ) (Range $5.7 \%$ to $53.2 \%$ ).

Of all the subjects, in $5.2 \%$ it was found that their body fat is less than seven percent of their weight.

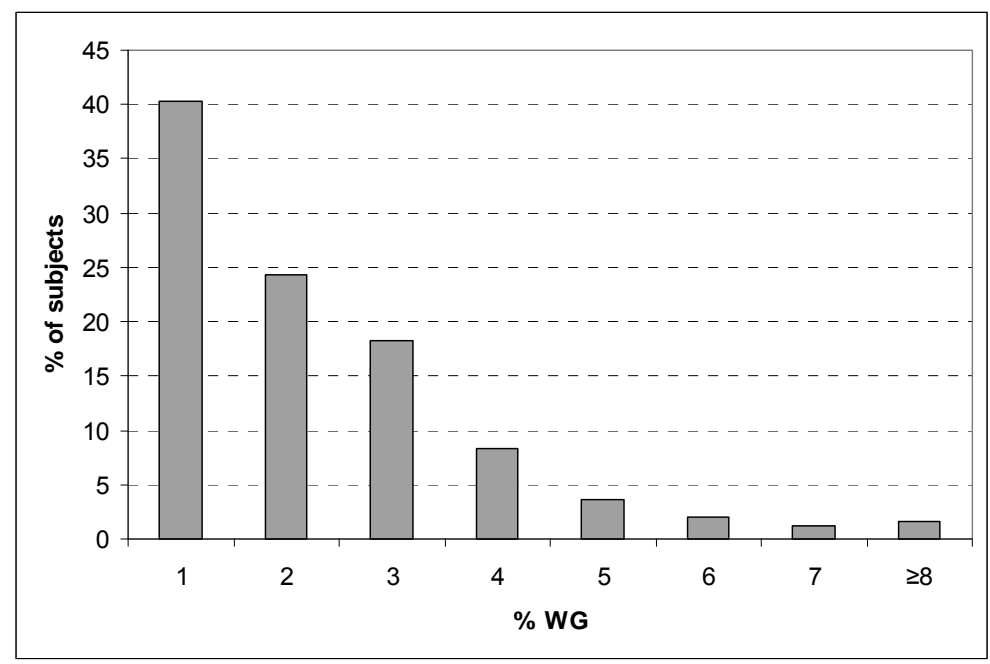

Fig. 1: Percentage of weight gain $(\% \mathrm{WG})$ [i.e. (weight gain/ weight at official weigh-in) $\times 100$ ] for the participants in the Tehran high school championship 


\section{DISCUSSION}

\section{Weight gain in competitions:}

The majority (69\%) of our subjects gained a mean of $1.3 \mathrm{~kg}(2.2 \%$ of their body mass) between weigh-in and competition. The magnitude of weight gain in our subjects was similar to the magnitude of weight gain in the selected high school wrestlers in the US cited by Wroble et al ${ }^{[19]}$. However, the time between official weigh-in and competition in our study was about 20 hours and in the study reported by Wroble et al ${ }^{[19]}$ was $12 \mathrm{~h}$. Alderman et al ${ }^{[21]}$ reported that high school wrestlers who participated in international style wrestling in the US gained a mean of $3.4 \mathrm{~kg}$ (4.8\% of their body mass) between weigh-in and the competition. This magnitude of weight gain was higher than the weight gain observed in high school wrestlers ${ }^{[19]}$. This is probably because the NCAA's weight loss rules were not applied to this competition since it is held under international style wrestling regulations ${ }^{[21]}$. The magnitude of weight gain in our series $(1.3 \mathrm{~kg}$, $2.2 \%$ of wrestler's body weight) was lower than that reported by Alderman et al $(3.4 \mathrm{~kg}, 4.8 \%$ of wrestler's body weight) ${ }^{[21]}$. In both series, the subjects competed under the international regulation of wrestling. This difference might suggest that the magnitude of weight loss among high school wrestlers in Tehran is lower than the same measurements for wrestlers in the US who also competed under the international regulation of wrestling. However, the difference might be partly because of the following reasons; 1) Weight gain in the series reported by Landers et al ${ }^{[21]}$ was measured for a national level competition. In our series, we recorded the weight gain for a lower level competition. It is reported that the level of the tournaments might be important in the magnitude of weight loss ${ }^{[20]}$. In the national tournaments the wrestlers might gain weight more than for the mid-season tournaments ${ }^{[20]}$. 2) In our study, $73 \%$ of participants in the championship agreed to participate in the study. Those who chose not to participate in the study might be those who reduce their weight more than others. Therefore, the survey results probably underestimate the magnitude of weight gain. 3) The management committee of the competition in our series gave $1 \mathrm{~kg}$ weight allowance to wrestlers of all weight classes. In other words, the wrestlers were allowed to have $1 \mathrm{~kg}$ more weight at weigh-in time compared to their weight classes regulated by the FILA. If we were to add $1 \mathrm{~kg}$ to the magnitude of weight gain practiced by the subjects, the percentage of weight gain will increase from $2.2 \%$ to $3.9 \%$ of the wrestlers' weight. Weight allowance for selected competitions might be beneficial for reducing the magnitude of weight loss and for reducing weight cycling practices in some wrestlers. However, there is an issue of fairness with this regulation.

\section{Body fat in wrestlers:}

The mean percentage of body fat in high school and collegiate wrestlers in the US as reported by different studies varies from $6 \%$ to $12.8 \%$; with a reported body fat ranging from $2.4 \%$ to $33.7 \%{ }^{[9,22-26]}$. The results of our study show that the percentage of body fat in participants of the Tehran high school championship (mean: $15.2 \%, 95 \% \mathrm{CI}=14.2 \%$ to $16.1 \%$ ) are relatively higher.

This might be because our subjects employed fewer fat reduction methods of weight loss. It is suggested that male wrestlers in the age group of 12 to 24 will not harm themselves if they reduce their body fat down to $7 \%$ of their weight ${ }^{[33]}$. Therefore, it seems that the majority of our subjects could safely reduce their body mass by reduction of their body fat. Reduction of body fat is a relatively safe method of weight loss in wrestling, providing that wrestlers rate of fat reduction is not more than 0.5 to $1 \mathrm{~kg}$ or $1.5 \%$ of their body mass per week $^{[17,33,34]}$.

It should be noted that $5 \%$ of participants at the Tehran High School Championship had less than 7\% body fat. Therefore, a further reduction of body fat for these groups of wrestlers may not be safe. The estimation of body fat by measuring skin-folds is safe, accurate, and relatively inexpensive. Luttermoser, et al [23] showed that using three quick skin-fold measurements obtained with the inexpensive plastic Ross calipers and a chart of values, minimum wrestling body mass could accurately be calculated. This practical method can be employed by coaches or sports medicine practitioners to identify the group of wrestlers who have less than $7 \%$ body fat.

Estimating body fat employing Lohman's equation and three point skin fold thickness measurement has 
been validated for male wrestlers between the ages of 12 and 24 years in the US. However, ethnic differences between American and Iranian wrestlers might be a limitation for this study.

\section{CONCLUSION}

We found that wrestlers in Iran mostly practice rapid
Iran. Designing well controlled prospective studies to find the proper weight loss methods with an optimum body fat percentage for the wrestlers should be considered as future topics of research for the investigators. In addition, more studies to find the effect of different weight loss programs on the performance of the wrestlers need to be done. weight loss methods and have a relatively higher body fat percentage in comparison to American wrestlers. It seems that educating the wrestlers regarding the safe and gradual methods of weight loss such as fat reduction methods should be put under greater emphasis by the coaches, sports physicians and all those who are in close contact with the wrestlers in

\section{ACKNOWLEDGMENTS}

Authors would like to thank the Sports Medicine Research Center of Tehran University of Medical Sciences that financially supported this project (Grant No: 2836).

\section{Conflict of interests: None}

\section{REFERENCES}

1. Kordi R, Akbarnejad A, Wallace WA. Catastrophic injuries in the Olympic styles of wrestling in Iran. Br J Sports Med 2010;44:16874.

2. Kordi R, Heidarpour B, Shafiei M, et al. Incidence, Nature, and Causes of Fractures and Dislocations in Olympic Styles of Wrestling in Iran: A 1-Year Prospective Study. Sports Health: A Multidisciplinary approach 2012;4:217-21.

3. Kordi R, Mansournia MA, Nourian RA, Wallace WA. Cauliflower ear and skin infections among wrestlers in Tehran. J Sport Sci Med 2007;6:39-44.

4. Kordi R, Neal K, Pourfathollah AA, et al. Risk of hepatitis B and C infections in tehranian wrestlers. J Athl Train 2011;46:445-50.

5. Kordi R, Wallace WA. The risk of transmission of blood borne infection in wrestling (a pilot study). Cell Mol Biol Lett 2004;9:34-5.

6. Kordi R, Wallace WA. Blood borne infections in sport: risks of transmission, methods of prevention, and recommendations for hepatitis B vaccination. Br J Sports Med 2004;38:678-84.

7. Kordi R, Ziaee V, Rostami M, Wallace W. Patterns of weight loss and supplement consumption of male wrestlers in Tehran. Sports Medicine, Arthroscopy, Rehabilitation, Therapy \& Technology 2011;3:4.

8. Kordi R, Ziaee V, Rostami M, Wallace WA. Indirect Catastrophic Injuries in Olympic Styles of Wrestling in Iran. Sports Health: A Multidisciplinary Approach 2011;3:29-31.

9. Oppliger RA, Case HS, Horswill CA, et al. American College of Sports Medicine position stand. Weight loss in wrestlers. Med Sci Sports Exerc 1996;28:ix-xii.

10. Steen SN, Brownell KD. Patterns of weight loss and regain in wrestlers: has the tradition changed? Med Sci Sports Exerc 1990, 22:762-8.

11. Marquart LF, Sobal J. Weight loss beliefs, practices and support systems for high school wrestlers. J Adolesc Health 1994; 15:410-5.

12. Oppliger RA, Case HS, Horswill CA, et al. American College of Sports Medicine position stand: Weight loss in wrestlers. Med Sci Sports Exerc 1996;28:135-8.

13. Kiningham RB, Gorenflo DW. Weight loss methods of high school wrestlers. Med Sci Sports Exerc 2001;33:810-3.

14. Schnirring L. Wrestling rules pin harmful weight cutting: fairness, validation concerns color debate. Phys Sportsmedicine 2002;30:79.

15. Oppliger RA, Steen SA, Scott JR. Weight loss practices of college wrestlers. Int J Sport Nutr Exerc Metab 2003;13:29-46. 
16. Tarnopolsky MA, Cipriano N, Woodcroft C, et al. Effects of rapid weight loss and wrestling on muscle glycogen concentration. Clin J Sport Med 1996;6:78-84.

17. NCAA. Wrestling, 2004 Rules and Interpretations. Indiana: National Collegiate Athletic Association; 2003.

18. Perriello Jr VA. Aiming for healthy weight in wrestlers and other athletes. Contemporary Pediatrics 2001;18:55-74.

19. Wroble RR, Moxley DP. Acute weight gain and its relationship to success in high school wrestlers. Med Sci Sports Exerc 1998; 30:949-51.

20. Scott JR, Horswill CA, Dick RW. Acute weight gain in collegiate wrestlers following a tournament weigh-in. Med Sci Sports Exerc 1994;26:1181-5.

21. Alderman BL, Landers DM, Carlson J, Scott JR. Factors related to rapid weight loss practices among international-style wrestlers. Med Sci Sports Exerc 2004;36:249-52.

22. Robergs RA, Roberts SO. Fundamental principles of exercise physiology: for fitness, performance, and health. Boston: McGraw-Hill 2000.

23. Luttermoser G, Gochenour D, Shaughnessy AF. Determining a minimum wrestling weight for interscholastic wrestlers. $J$ Fam Pract 1999;48:208-12.

24. Clark RR, Oppliger RA, Sullivan JC. Cross-validation of the NCAA method to predict body fat for minimum weight in collegiate wrestlers. Clin J Sport Med 2002;12:285-90.

25. Clark RR, Sullivan JC, Bartok C, Schoeller DA. Multicomponent cross-validation of minimum weight predictions for college wrestlers. Med Sci Sports Exerc 2003;35:342-7.

26. Clark RR, Kuta JM, Sullivan JC, et al. A comparison of methods to predict minimal weight in high school wrestlers. Med Sci Sports Exerc 1993;25:151-8.

27. Sahand b. basculesahand. Tabriz, 2006. Available at: http://www.basculesahand.com/p1.html. Access date: Mar 2011.

28. Minnesota State High School League: Minimum Weight Permit Form. Available at: http://www.mshsl.org/mshsl/activitypage.asp? actnum=424. Access date: Dec , 2005.

29. Wagner DR. Body composition assessment and minimal weight recommendations for high school wrestlers. J Athl Train 1996; 31:262-5.

30. Roberts WO. Certifying wrestlers' minimum weight: a new requirement. Phys Sportsmedicine 1998;26:79-81.

31. Thorland WG, Tipton CM, Lohman TG, et al. Midwest wrestling study: prediction of minimal weight for high school wrestlers. Med Sci Sports Exerc 1991;23:1102-10.

32. Bartok C, Schoeller DA, Randall Clark R, et al. The effect of dehydration on wrestling minimum weight assessment. Med Sci Sports Exerc 2004;36:160-7.

33. Kuehn BM. Pediatricians Warned About Student Athletes' Risky Weight-Control Tactics. JAMA 2006, 295:486.

34. Maughan RJ, Burke L, IOC Medical Commission. Sports Nutrition. Malden, Mass; Oxford: Blackwell Science. 2002. 